Muhammad Ali Javed, Moritz Rüther, Elmar Baumhögger, Jadran Vrabec

\title{
Density and Thermodynamic Speed of Sound of Liquid Vinyl Chloride
}

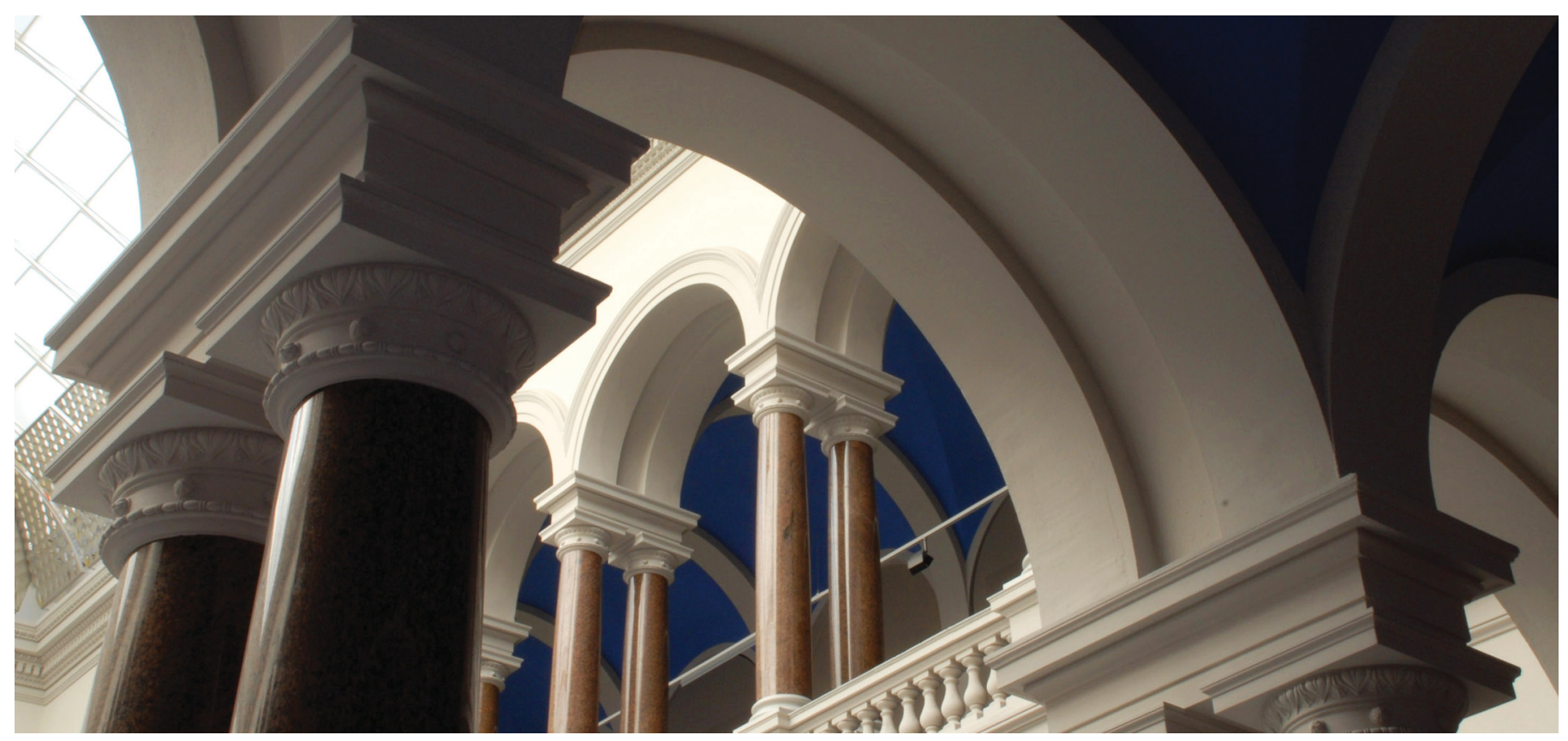

Javed, M. A., Rüther, M., Baumhögger, E., \& Vrabec, J. (2020). Density and Thermodynamic Speed of Sound of Liquid Vinyl Chloride. Journal of Chemical \& Engineering Data, 65(5), 2495-2504. https://doi.org/10.1021/acs.jced.9b01133 


\title{
Density and thermodynamic speed of sound of liquid vinyl chloride
}

\author{
Muhammad Ali Javed, ${ }^{\dagger}$ Moritz Rüther, ${ }^{\ddagger}$ Elmar Baumhögger ${ }^{\ddagger}$ and Jadran \\ $\operatorname{Vrabec}^{*, \dagger}$ \\ $\dagger$ Thermodynamics and Process Engineering, Technical University of Berlin, 10623 Berlin, \\ Germany \\ $\ddagger$ Thermodynamics and Energy Technology, University of Paderborn, 33098 Paderborn, \\ Germany \\ E-mail: vrabec@tu-berlin.de
}

\begin{abstract}
Vinyl chloride is one of the world's most important industrially synthesized substances, but due to its physico-chemical nature comparably little is known about its thermodynamic behavior. Accurate density and thermodynamic speed of sound data of vinyl chloride in the liquid state are measured along nine isotherms, covering the temperature range from $283 \mathrm{~K}$ to $362 \mathrm{~K}$ up to a pressure of $91 \mathrm{MPa}$. Data are presented with a maximum expanded uncertainty $(k=2)$ of $0.15 \%$ for the density and $0.16 \%$ for the speed of sound. They are compared with all available literature sources and a preliminary equation of state. Present density data are in good agreement with the literature data and have a maximum deviation of $1.5 \%$ from the equation of state. However, no experimental speed of sound data are available in the literature for comparison and the equation of state diverges up to $-12.4 \%$ from the present data.
\end{abstract}

keywords: Density, speed of sound, densimeter, pulse-echo technique, vinyl chloride. 


\section{Introduction}

Vinyl chloride, a common name for chloroethene, chloroethylene, ethylene monochloride or monochloroethylene, is under ambient conditions a colorless and combustible gas with a mildly sweet odor. It is one of the world's most important industrial commodity chemicals, but it can also be formed in the environment, when chlorinated solvents are broken down by soil microorganisms. ${ }^{1,2}$ Vinyl chloride is toxic for humans, since acute or short-term exposure during respiration damages the central nervous system, while long-term exposure results in liver cancer. ${ }^{1,3}$

The global production of vinyl chloride monomer was 49 million metric tons in 2018 and it is expected to reach 53 million metric tons by $2023 .{ }^{4}$ Northeast Asia is currently the largest consumer of vinyl chloride, utilizing more than half of its total production. China is the biggest player in the vinyl chloride industry, consuming about $40 \%$ of its total yield, while the United States is in the second place. ${ }^{5}$

Vinyl chloride was commercially produced for the first time in the 1930s. Currently, it is synthesised by direct chlorination or oxychlorination of ethylene. As a result of both processes, 1,2-dichloroethane is obtained, which is subjected to a pressure of about $3 \mathrm{MPa}$ at a temperature of $550{ }^{\circ} \mathrm{C}$. This causes 1,2-dichloroethane to undergo pyrolysis or thermal cracking, forming vinyl chloride monomer and hydrogen chloride, from which vinyl chloride is isolated. ${ }^{1,6}$

Almost $99 \%$ of the total production of vinyl chloride is used for making polyvinyl chloride (PVC), which contains repeating units of vinyl chloride monomer in long chains. This polymer is commonly utilized with great flexibility to make end products, including pipes and fittings, profiles and tubes, siding, wire coating, housewares and automotive parts. The vinyl chain, containing ethylene dichloride, vinyl chloride monomer and polyvinyl chloride, is a main component of the petrochemical and thermoplastic industry. ${ }^{5}$ Vinyl chloride is also used to produce methyl chloroform and copolymers with vinyl acetate, vinyl stearate and 
vinylidene chloride. ${ }^{1}$ In the past, vinyl chloride was used as a refrigerant, propellant in spray cans and in some cosmetics, but these practices have been officially banned since the 1970s. ${ }^{1}$

Because vinyl chloride has critical health and fire hazards and can easily undergo polymerization reactions, ${ }^{15}$ very limited experimental data for the density and no data for the speed of sound have been reported in the literature, cf. Table 1. Eight authors have measured the density in the liquid phase, covering the temperature range from $213 \mathrm{~K}$ to $423 \mathrm{~K}$ up to a maximum pressure of $4.2 \mathrm{MPa}$, cf. Figure 1 . However, most have measured only along the vapor pressure line. Cullick and Ely ${ }^{12}$ as well as Zerfa and Brooks ${ }^{14}$ have investigated higher pressures, but the latter have reported only a single data point.

Density and the speed of sound data, covering wide temperature and pressure ranges, are necessary for the development and parameterization of Helmholtz energy equations of state. ${ }^{16}$ As the global demand for vinyl chloride is increasing rapidly, ${ }^{5}$ a precise equation of state is beneficial for the design and optimization of industrial chemical processes. However, the currently available literature data for vinyl chloride are insufficient to properly parameterize such models. Nonetheless, a preliminary Helmholtz energy equation of state of Thol and Span ${ }^{17}$ exists.

In the present work, an apparatus was built to simultaneously measure the density and speed of sound of vinyl chloride. To suppress the risk of polymerization, copper wires were avoided and hydroquinone was placed in the rig as a stabilizer. ${ }^{18}$ The measurements were performed in the liquid phase, covering the temperature range from $283 \mathrm{~K}$ to $362 \mathrm{~K}$ up to a pressure of $91 \mathrm{MPa}$. The density was measured with an Anton Paar densimeter (DMAHPM) with a maximum expanded uncertainty of $0.15 \%(k=2)$. The speed of sound was investigated by employing a double path length pulse-echo technique with a maximum expanded uncertainty of $0.16 \%(k=2)$. The obtained results were compared with the available literature data and the preliminary Helmholtz energy equation of state of Thol and Span. ${ }^{17}$ 


\section{Experiment}

\subsection{Materials}

The specifications of the materials and details of their suppliers are provided in Table 2. They were purchased under high purity and studied without any further purification, except for degassing the liquid water sample.

\subsection{Apparatus}

An apparatus was developed to simultaneously sample the density and the speed of sound of vinyl chloride. For this purpose, a densimeter and an acoustic cell were combined. The schematic of the experimental rig is presented in Figure 2. To specify a temperature, both measurement devices were connected to a thermostat (Huber CC415). Therein, water was circulated as a heat transfer medium to regulate and maintain the temperature of the sample fluid within $0.01 \mathrm{~K}$. The temperature was varied between $283 \mathrm{~K}$ and $362 \mathrm{~K}$, remaining about $11 \mathrm{~K}$ below the normal boiling point of water to prevent excessive evaporation and to protect the circulating pump and electric circuits from damage caused by moisture. A hand pump (HIP 50-6-15) was employed to impose a pressure of up to $91 \mathrm{MPa}$ that was measured by a pressure transducer (Keller-PAA-33X).

Vinyl chloride is a highly unstable monomer and undergoes rapid polymerization reactions to form polyvinyl chloride (PVC) by heating and under the influence of air, sunlight and contact with strong oxidizers and metals, i.e. copper and aluminum. ${ }^{15}$ It is a gas under ambient conditions and its mixture with air forms peroxide, which may explode. ${ }^{19}$ Moreover, in the presence of moisture, vinyl chloride reacts with iron or steel. To mitigate this risk, the copper quantity in the apparatus was reduced to a minimum level and crystalline hydroquinone was used to prevent spontaneous polymerization. ${ }^{18}$ As this stabilizer is not soluble in vinyl chloride, almost $5 \mathrm{~g}$ of it was placed in a container with a porous lid behind 


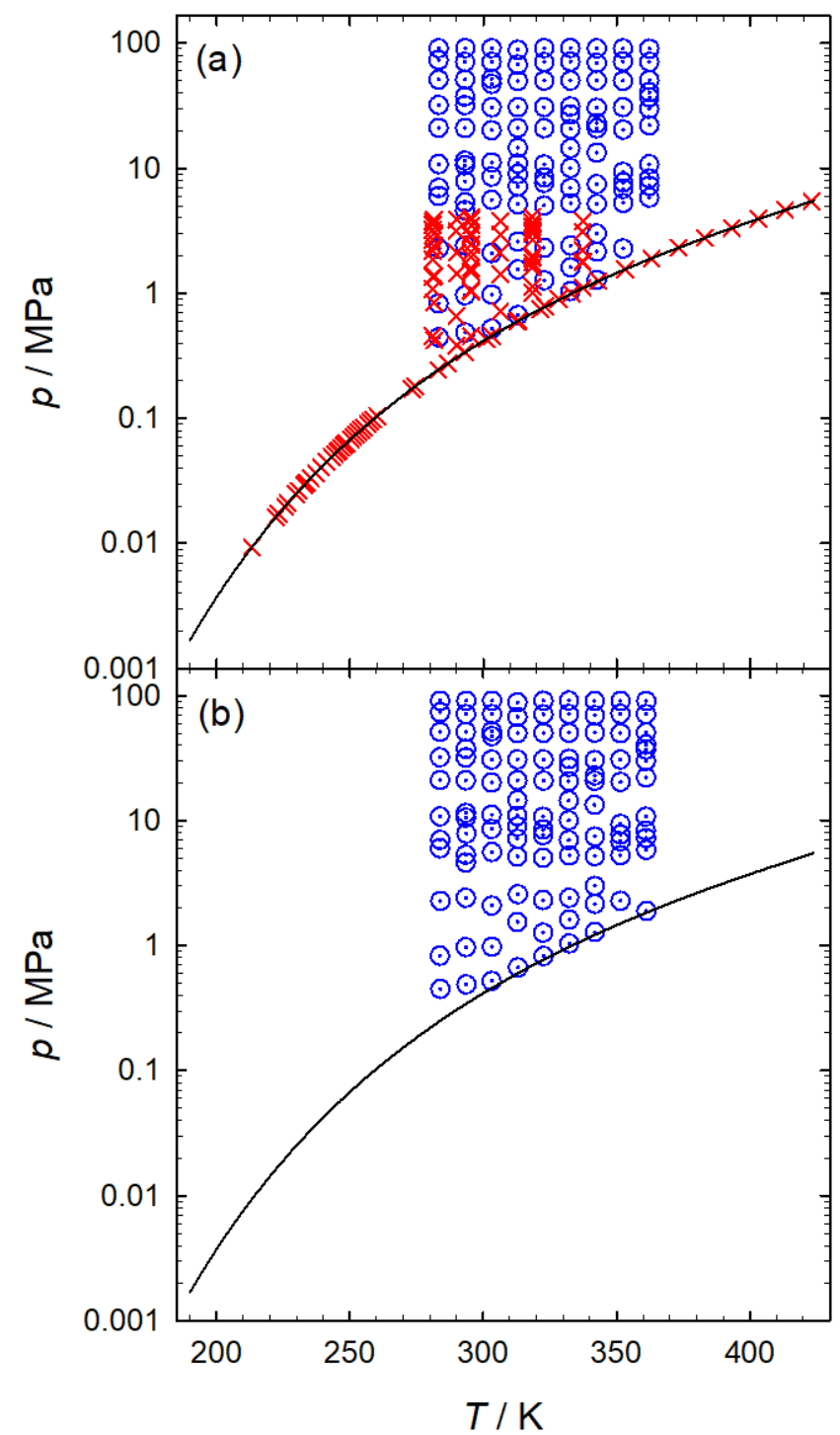

Figure 1: State points where (a) density and (b) speed of sound of vinyl chloride were measured: $\odot$ this work, $\times$ experimental literature data. The solid line is the vapor pressure curve. 
one of the reflectors, cf. Figure 3. The diameter of the lid pores was smaller than the crystal size of hydroquinone, keeping it in the container. The acoustic cell with the container was screwed into the ceiling of the pressure vessel. The cell was suspended in the sample fluid and to uniformly fill it, reflectors with cavity spacers were used.

\subsection{Density measurement}

The density of vinyl chloride was measured with an Anton Paar densimeter (DMA-HPM). Therein, a U-shaped metallic vibrating tube is connected to an interface module, which generates an oscillation and measures its period and temperature of the tube containing the sample fluid. The oscillation period is a function of density, temperature and pressure. To accurately determine the density of vinyl chloride, the densimeter was calibrated with propane and water on the basis of reference quality Helmholtz energy equations of state by

Lemmon et al. ${ }^{20}$ and Wagner and Pruß ${ }^{21}$ that are available for these substances. ${ }^{22}$ These fluids were chosen since they envelop the density range of vinyl chloride.

For calibration, the density of propane and water at different state points was fitted as a function of the measured oscillation period, temperature and pressure. ${ }^{16} \mathrm{~A}$ third order Legendre polynomial containing ten coefficients was used for this purpose

$$
\begin{aligned}
\rho= & a+b_{1} \underline{T}+c_{1} \underline{p}+d_{1} \underline{s}+b_{2} \frac{\left(3 \underline{T}^{2}-1\right)}{2}+d_{2} \frac{\left(3 \underline{s}^{2}-1\right)}{2} \\
& +b_{1} d_{1} \underline{T s}+b_{1} d_{2} \underline{T} \frac{\left(3 \underline{s}^{2}-1\right)}{2}+c_{1} d_{2} \frac{\left(3 \underline{s}^{2}-1\right)}{2} \\
& +b_{1} c_{1} d_{1} \underline{T} \underline{p} \underline{s} .
\end{aligned}
$$

Therein, $\underline{T}, \underline{p}$ and $\underline{s}$ are scaled parameters used to enhance the performance of the polynomial, defined by

$$
\underline{y}=\frac{y-\bar{y}}{\delta y} .
$$




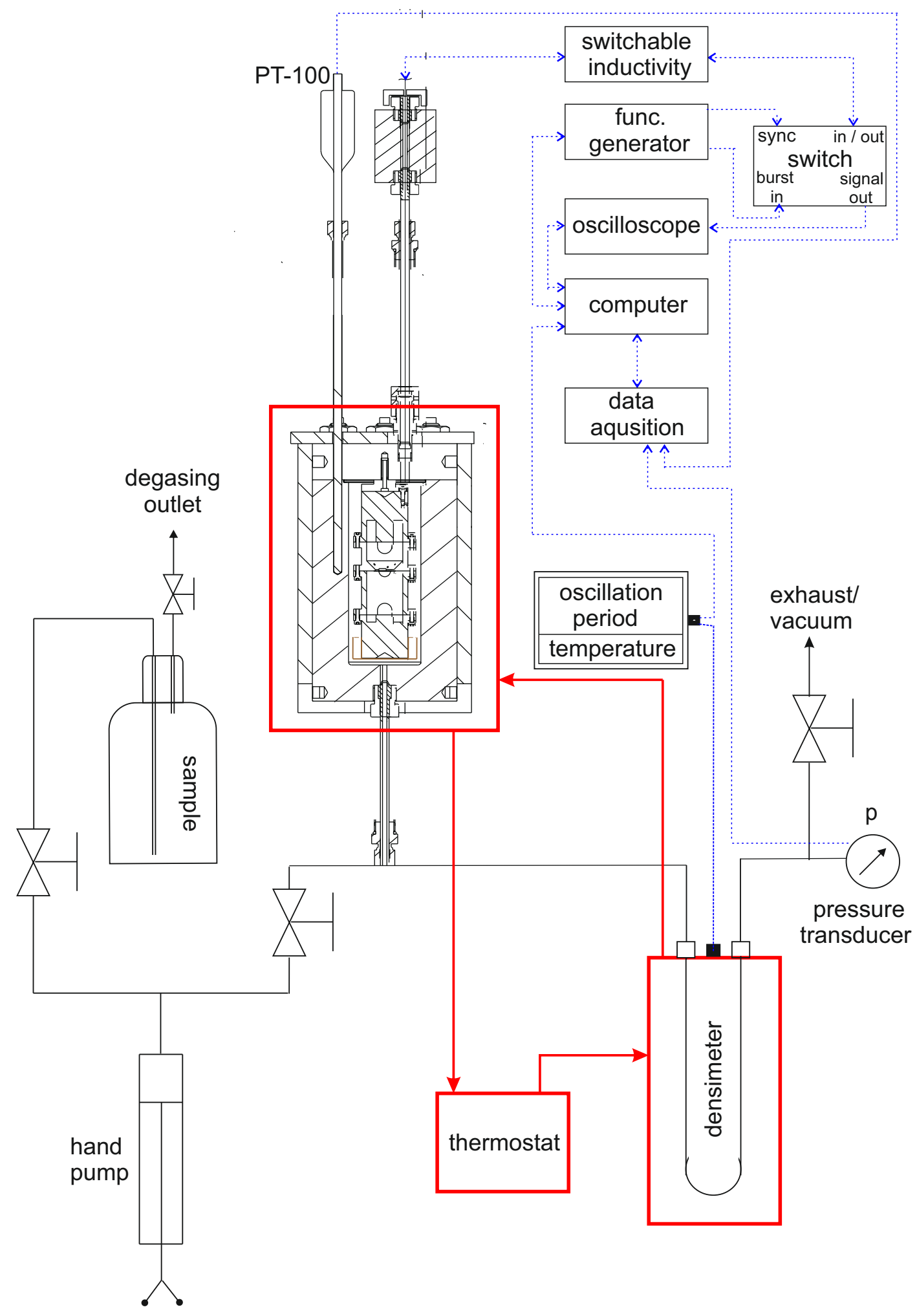

Figure 2: Schematic of the apparatus for measuring density and speed of sound along with the instruments for control and analysis. 
Table 1: Experimental density and the speed of sound data for vinyl chloride, where $N$ is the number of measured data points, $T_{\min }-T_{\max }$ the temperature range and $p_{\max }$ the maximum pressure.

\begin{tabular}{ccccccc}
\hline author & year & $N$ & $T_{\min }-T_{\max } / \mathrm{K}$ & $p_{\max } / \mathrm{MPa}$ & $U_{\rho} /\left(\mathrm{kg} \mathrm{m}^{-3}\right)$ & $U_{w} /\left(\mathrm{m} \mathrm{s}^{-1}\right)$ \\
\hline density & 1927 & 7 & $260-333$ & vapor pressure & 0.7 & - \\
Dana et al. & & & & \\
Mizutani and Yamashita $^{8}$ & 1950 & 27 & $222-259$ & vapor pressure & - & - \\
Dreisbach $^{9}$ & $1952-1955$ & 3 & $243-253$ & vapor pressure & - & - \\
Anonymous $^{10}$ & 1965 & 1 & 260 & vapor pressure & - & - \\
Hannaert et al. $^{11}$ & 1967 & 2 & $213-233$ & vapor pressure & 8.3 & - \\
Cullick and Ely $^{12}$ & 1982 & 68 & $281-337$ & 4.2 & 0.4 & - \\
de Loos et al. $^{13}$ & 1983 & 16 & $273-423$ & vapor pressure & 1.4 & - \\
Zerfa and Brooks $^{14}$ & 1996 & 1 & 328 & 0.9 & - & - \\
$\quad$ this work & 2019 & 107 & $283.3-362.2$ & 91.07 & 1.1 & - \\
speed of sound & & & & & & \\
this work & 2019 & 109 & $283.97-361.1$ & 91.06 & - & 1.1 \\
\hline
\end{tabular}

Table 2: Specification of the materials and their suppliers.

\begin{tabular}{ccccc}
\hline chemical name & CAS number & source & purity $/ \%$ & purification method \\
\hline hydroquinone & $123-31-9$ & Sigma-Aldrich & 100.00 & none \\
propane & $74-98-6$ & Gerling Holz \& Co. & 99.50 & none \\
vinyl chloride & $75-01-4$ & Sigma-Aldrich & 99.96 & none \\
water & $7732-18-5$ & Merck & 99.99 & none \\
\hline
\end{tabular}

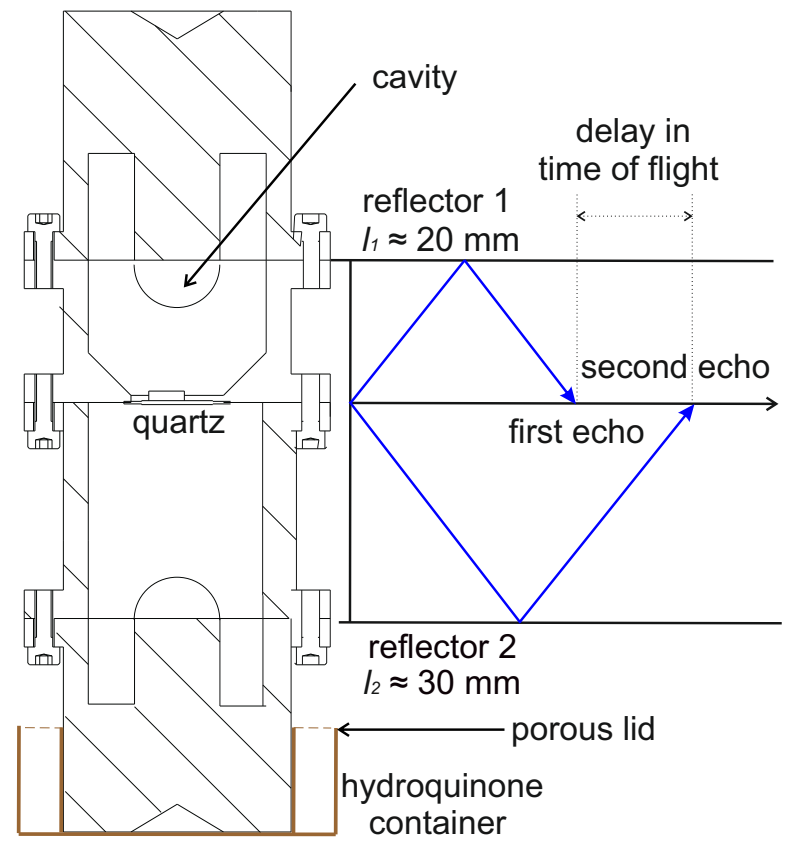

Figure 3: Working principle of the speed of sound measurement. 
The parameters of the calibration equation (1) are listed in Table 3. A comparison of the calibration measurements with the reference equations of state for propane and water is presented in Figure 4. In the liquid region, these equations of state have very low uncertainties of $0.01 \%$ for propane and $0.003 \%$ for water. It is convincing that the calibration measurements are in very good agreement with the equations of state, exhibiting a maximum deviation of less than $0.04 \%$ for propane and about $0.01 \%$ for water. Also at elevated pressures, present measurements are consistent with the reference equations.

Table 3: Parameters of the calibration equation (1) for the density measurement.

\begin{tabular}{ccl}
\hline parameter & value & unit \\
\hline$a$ & 750.0756 & - \\
$b_{1}$ & -359.6746 & - \\
$c_{1}$ & -4.9587 & - \\
$d_{1}$ & 767.7276 & - \\
$b_{2}$ & -2.7453 & - \\
$d_{2}$ & 1.4900 & - \\
$b_{1} d_{1}$ & -14.0967 & - \\
$b_{1} d_{2}$ & 2.0918 & - \\
$c_{1} d_{2}$ & -3.6169 & - \\
$b_{1} c_{1} d_{1}$ & 4.2310 & - \\
$\bar{T}$ & 57.077 & ${ }^{\circ} \mathrm{C}$ \\
$\delta T$ & 80 & ${ }^{\circ} \mathrm{C}$ \\
$\bar{p}$ & 46.059 & $\mathrm{MPa}$ \\
$\delta p$ & 47.0 & $\mathrm{MPa}$ \\
$\bar{s}$ & 2646.468 & $\mu \mathrm{s}$ \\
$\delta s$ & 60 & $\mu \mathrm{s}$ \\
\hline
\end{tabular}

\subsection{Speed of sound measurement}

The thermodynamic speed of sound was measured with a double path length pulse-echo technique. ${ }^{23-26}$ To bring this method into practice, an $8 \mathrm{MHz}$ gold plated piezoelectric quartz crystal was placed symmetrically between two metallic reflectors of unequal lengths. The quartz was excited electrically with a functional generator (Agilent 33220A). Consequently, two sound waves emerged, traveled in opposite directions, and after reflection, were received back by the quartz at different time instances. These echoes were analyzed with an oscil- 


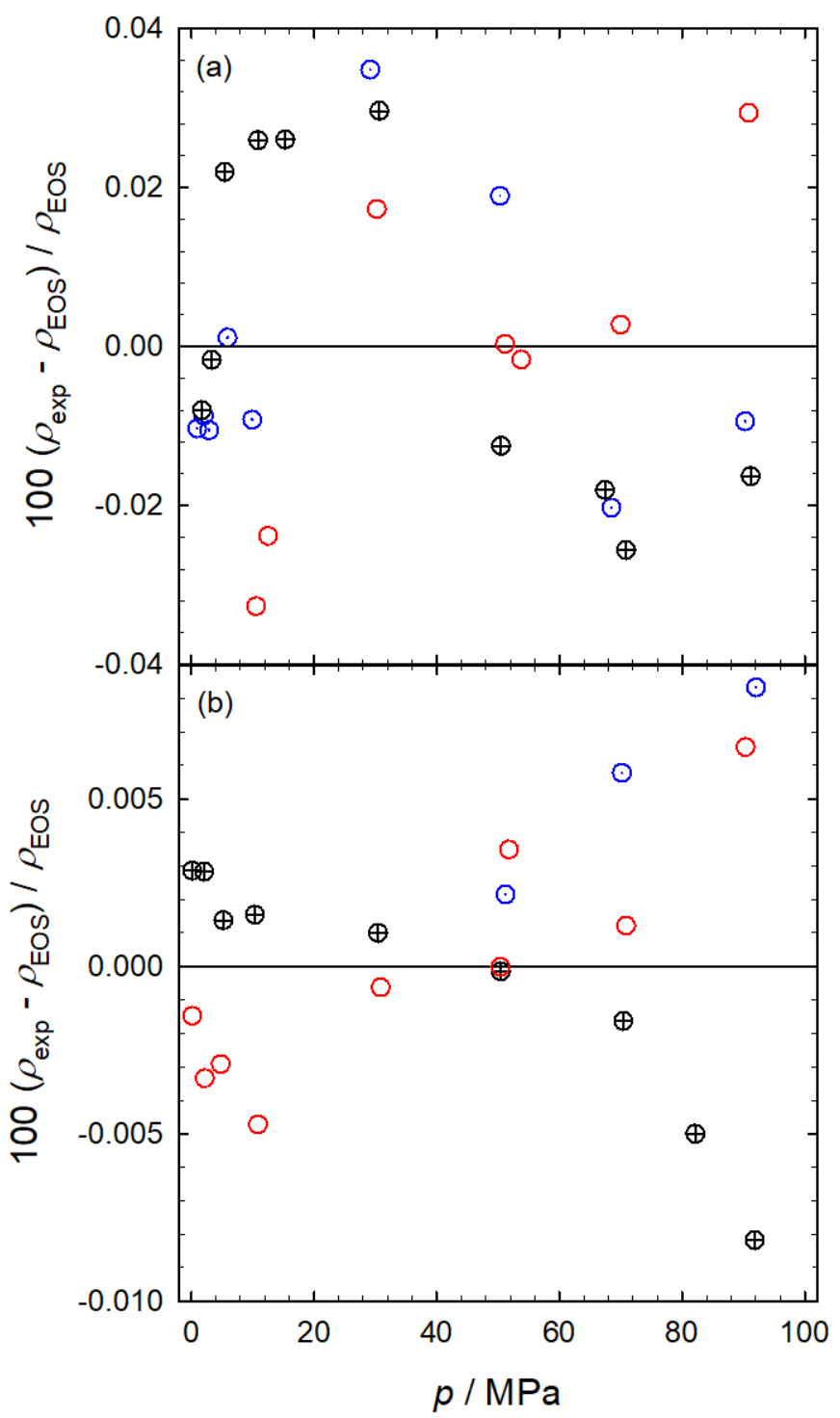

Figure 4: Comparison of the calibration measurements for density as a function of pressure along isotherms: $\odot 298 \mathrm{~K}, \oplus 323 \mathrm{~K}, \bigcirc 362 \mathrm{~K}$; (a) propane, where the baseline is the equation of state by Lemmon et al. ${ }^{20}$ (b) water, where the baseline is the equation of state by Wagner and Pruß. ${ }^{21}$ 
loscope (Agilent DSO1022A) and, neglecting diffraction and dispersion effects, the speed of sound was calculated by

$$
w=\frac{2 \Delta L}{\Delta t}
$$

where $\Delta L$ is the path length difference between the two reflectors and $\Delta t$ is the delay in time of flight of the two echoes.

The path length difference $\Delta L\left(T_{0}, p_{0}\right)=9.99 \mathrm{~mm}$ at $T_{0}=300 \mathrm{~K}$ and $p_{0}=1 \mathrm{MPa}$ was determined from calibration measurements with water. In order to achieve this, the equation of state by Wagner and Pruß ${ }^{21}$ was employed, which has an uncertainty of $0.005 \%$ for the speed of sound calculation at the selected state point. Thermal expansion and pressure compression of the acoustic cell, fabricated from stainless steel (type 1.4571) were considered by

$$
\Delta L(T, p)=\Delta L\left(T_{0}, p_{0}\right)\left[1+\bar{\alpha}-\frac{1}{E}(1-2 \nu)\left(p-p_{0}\right)\right]
$$

Therein, $\nu=0.3$ is the Poisson number, provided by the steel supplier. The integral thermal expansion coefficient $\bar{\alpha}$ was calculated by

$$
\begin{aligned}
\bar{\alpha}= & n_{0}\left(T-T_{0}\right)+\frac{n_{1}}{2}\left(T^{2}-T_{0}^{2}\right)+\frac{n_{2}}{3}\left(T^{3}-T_{0}^{3}\right) \\
& +\frac{n_{3}}{4}\left(T^{4}-T_{0}^{4}\right)+\frac{n_{4}}{5}\left(T^{5}-T_{0}^{5}\right)
\end{aligned}
$$

where $n_{0}=4.7341 \cdot 10^{-6} \mathrm{~K}^{-1}, n_{1}=7.1518 \cdot 10^{-8} \mathrm{~K}^{-2}, n_{2}=-1.5273 \cdot 10^{-10} \mathrm{~K}^{-3}, n_{3}=$ $1.5864 \cdot 10^{-13} \mathrm{~K}^{-4}$ and $n_{4}=-6.1342 \cdot 10^{-17} \mathrm{~K}^{-5} \cdot{ }^{27}$ The temperature dependent modulus of elasticity $E$ contributed with a first order polynomial

$$
E=a+b(T)
$$

where $a=219711.07 \mathrm{MPa}^{-1}$ and $b=-79.8 \mathrm{~K}^{-1} \mathrm{MPa}^{-1} .{ }^{27}$ 
To measure the delay in time of flight, a peak-to-peak measurement method, which considers the time difference between maximum amplitudes of both echoes, and a correlation approach, were adapted. For the correlation method, a time domain analysis was performed, in which two data cuts were made for both echoes and the delay in time of flight was determinded by applying a correlation function. Details were recently described by Javed et al. ${ }^{28}$

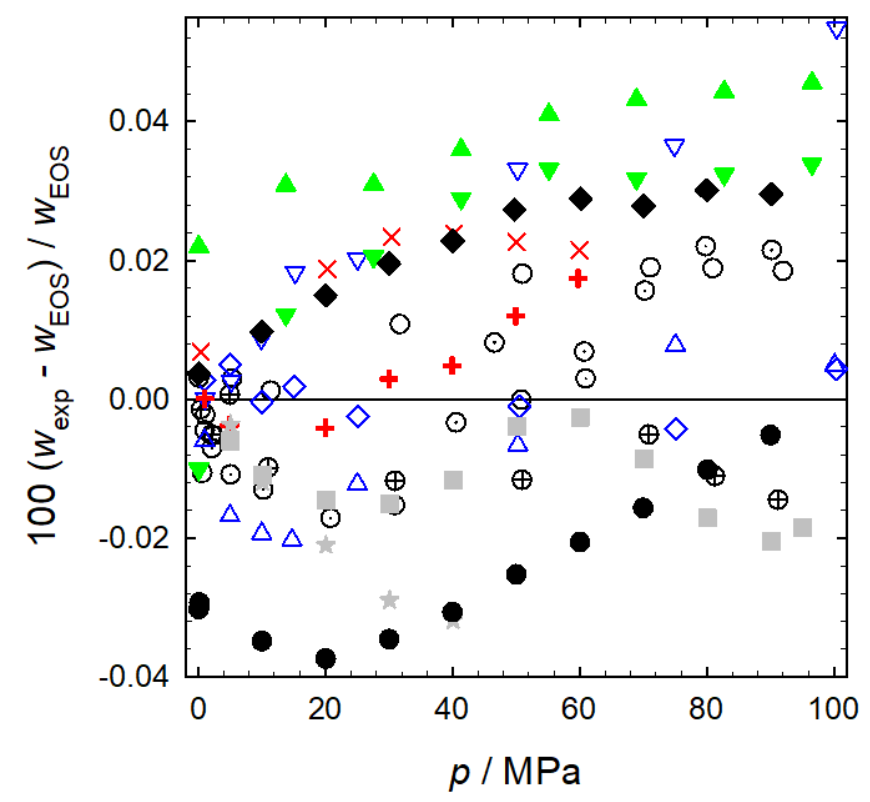

Figure 5: Comparison of the calibration measurements for speed of sound with the equation of state by Wagner and Pruß. ${ }^{21}$ Experimental data: this work, $\odot 298 \mathrm{~K}, \oplus 323 \mathrm{~K}, \bigcirc 361$ $\mathrm{K}$; Lin and Trusler, ${ }^{29} \triangle 303 \mathrm{~K}, \diamond 323 \mathrm{~K}, \nabla 373 \mathrm{~K}$; Al Ghafri et al., ${ }^{30}+306 \mathrm{~K}, \times 358 \mathrm{~K}$; Wilson, ${ }^{31} \Delta 303 \mathrm{~K}, \nabla 364 \mathrm{~K}$; Yebra et al., ${ }^{32} \square 303 \mathrm{~K}, \star 323 \mathrm{~K}$; Benedetto et al., ${ }^{33} \bullet 303$ $\mathrm{K}, \diamond 364 \mathrm{~K}$.

A comparison of the calibration measurements with the equation of state by Wagner and Pru $\S^{21}$ and the experimental literature data is shown in Figure 5. The literature data have a maximum uncertainty of about $0.04 \%$. It should be noted that the calibration measurements of this work are in very good agreement with the equation of state, exhibiting a maximum deviation of $0.02 \%$ for the entire measured temperature and pressure range. 


\section{Results and discussion}

Vinyl chloride was delivered in a metal flask as a saturated liquid at ambient temperature and 0.4 MPa pressure. To measure its density and speed of sound, the apparatus was evacuated for about $2 \mathrm{~h}$ and the system temperature was reduced to $283 \mathrm{~K}$. Subsequently, vinyl chloride was imbibed into the apparatus and a pressure was specified with the hand pump. Density and speed of sound were measured along nine isotherms between $283 \mathrm{~K}$ and $362 \mathrm{~K}$ with an increment of $10 \mathrm{~K}$ up to a pressure of $91 \mathrm{MPa}$. The sample fluid was given an equilibration time of about $1.25 \mathrm{~h}$, before measuring the next state point.

\subsection{Density}

The numerical density data for vinyl chloride together with their uncertainties are listed in Table 4. The overall expanded uncertainty at a confidence level of $95 \%$ was calculated by considering the individual uncertainties of temperature $u_{T}$, pressure $u_{p}$, oscillation period $u_{s}$, calibration $u_{\text {cal }}$ and impurities $u_{\text {imp }}$

$$
U_{\rho}=k\left[\left(\frac{\partial \rho}{\partial T}\right)_{p, s}^{2} u_{T}^{2}+\left(\frac{\partial \rho}{\partial p}\right)_{T, s}^{2} u_{p}^{2}+\left(\frac{\partial \rho}{\partial s}\right)_{T, p}^{2} u_{s}^{2}+u_{\mathrm{cal}}^{2}+u_{\mathrm{imp}}^{2}\right]^{1 / 2}
$$

with the coverage factor $k=2$. The partial derivatives of density with respect to temperature and pressure were calculated with the Helmholtz energy equation of state by Thol and Span. ${ }^{17}$ The partial derivative with respect to oscillation period was obtained from equation (1). A detailed uncertainty budget for the density measurement is provided in Table 5. It should be noted that the major contribution to the overall uncertainty, i.e. $0.109 \%$, is due to calibration, which also includes reproducibility of the data and aging of the densimeter.

The graphical presentation of experimental uncertainty as a function of pressure along different isotherms is provided in Figure 6 . The uncertainty varies between $0.11 \%$ to $0.15 \%$ for the entire measured temperature and pressure range. The maximum uncertainty is at 


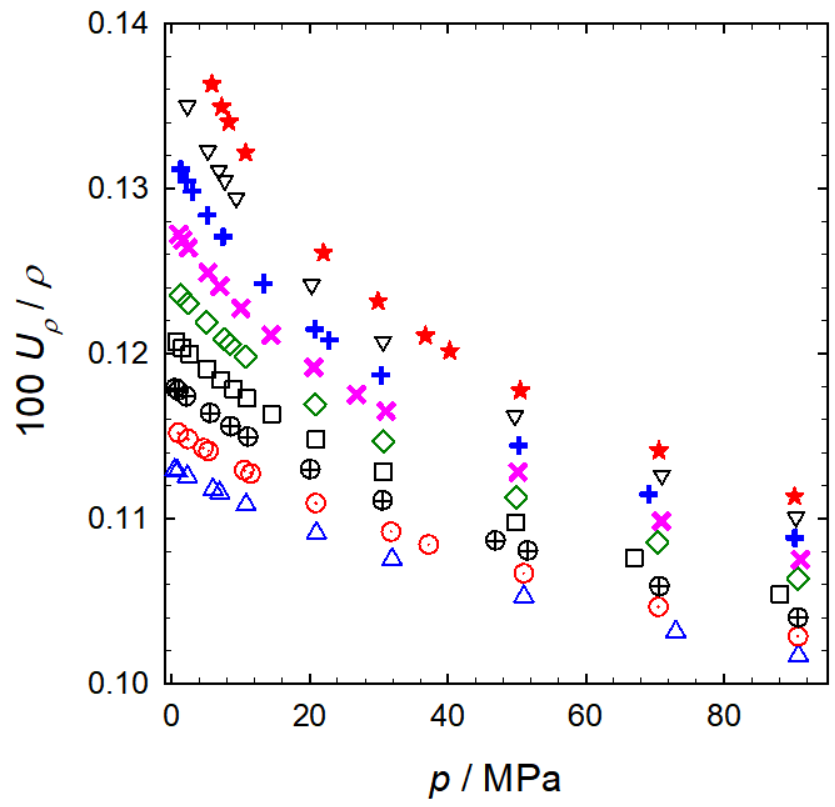

Figure 6: Experimental uncertainty of the density of vinyl chloride as a function of pressure along different isotherms: $\triangle 283 \mathrm{~K}, \odot 293 \mathrm{~K}, \oplus 303 \mathrm{~K}, \square 313 \mathrm{~K}, \diamond 323 \mathrm{~K}, \times 333 \mathrm{~K},+343$ $\mathrm{K}, \nabla 352 \mathrm{~K}, \star 362 \mathrm{~K}$.

$262 \mathrm{~K}$ and 5.8 MPa.

Table 4: Density of vinyl chloride with its expanded experimental uncertainty for varying temperature $T$ and pressure $p$.

\begin{tabular}{cccccccc}
\hline$T / \mathrm{K}$ & $p / \mathrm{MPa}$ & $\rho /\left(\mathrm{kg} \mathrm{m}^{-3}\right)$ & $U_{\rho} /\left(\mathrm{kg} \mathrm{m}^{-3}\right)$ & $T / \mathrm{K}$ & $\rho / \mathrm{MPa}$ & $\rho /\left(\mathrm{kg} \mathrm{m}^{-3}\right)$ & $U_{\rho} /\left(\mathrm{kg} \mathrm{m}^{-3}\right)$ \\
\hline 283.3 & 0.44 & 927.8 & 1.1 & 322.8 & 10.69 & 877.4 & 1.1 \\
283.3 & 0.83 & 928.4 & 1.1 & 322.9 & 20.78 & 898.4 & 1.1 \\
283.3 & 2.27 & 931.1 & 1.1 & 322.9 & 30.62 & 915.7 & 1.1 \\
283.3 & 5.98 & 937.6 & 1.1 & 322.9 & 49.89 & 943.5 & 1.1 \\
283.3 & 6.95 & 939.2 & 1.1 & 322.9 & 70.36 & 967.7 & 1.1 \\
283.3 & 10.76 & 945.4 & 1.1 & 322.9 & 90.68 & 988.1 & 1.1 \\
283.3 & 20.97 & 960.4 & 1.1 & 332.7 & 1.03 & 830.6 & 1.1 \\
283.3 & 31.91 & 974.6 & 1.1 & 332.7 & 1.61 & 832.6 & 1.1 \\
283.3 & 51.01 & 996.1 & 1.1 & 332.8 & 2.4 & 835.3 & 1.1 \\
\hline
\end{tabular}


Table 4 : (Continued)

\begin{tabular}{cccccccc}
\hline$T / \mathrm{K}$ & $p / \mathrm{MPa}$ & $\rho /\left(\mathrm{kg} \mathrm{m}^{-3}\right)$ & $U_{\rho} /\left(\mathrm{kg} \mathrm{m}^{-3}\right)$ & $T / \mathrm{K}$ & $p / \mathrm{MPa}$ & $\rho /\left(\mathrm{kg} \mathrm{m}^{-3}\right)$ & $U_{\rho} /\left(\mathrm{kg} \mathrm{m}^{-3}\right)$ \\
\hline 283.3 & 73 & 1017 & 1.1 & 332.8 & 5.24 & 844.3 & 1.1 \\
283.3 & 90.77 & 1031.9 & 1.1 & 332.7 & 6.95 & 849.4 & 1.1 \\
293.2 & 0.96 & 910.5 & 1.1 & 332.7 & 10.02 & 857.8 & 1.1 \\
293.2 & 2.4 & 913.4 & 1.1 & 332.7 & 14.4 & 868.7 & 1.1 \\
293.2 & 4.6 & 917.8 & 1.1 & 332.7 & 20.56 & 882.2 & 1.1 \\
293.2 & 5.31 & 919.1 & 1.1 & 332.7 & 26.77 & 894.3 & 1.1 \\
293.2 & 10.5 & 928.5 & 1.1 & 332.7 & 31.05 & 902 & 1.1 \\
293.2 & 11.45 & 930.2 & 1.1 & 332.7 & 50.18 & 931.3 & 1.1 \\
293.2 & 20.89 & 945.2 & 1.1 & 332.7 & 70.92 & 957 & 1.1 \\
293.2 & 31.77 & 960.3 & 1.1 & 332.7 & 91.07 & 977.9 & 1.1 \\
293.2 & 37.25 & 967.1 & 1.1 & 342.6 & 1.28 & 808.6 & 1.1 \\
293.2 & 51.02 & 983.2 & 1.1 & 342.6 & 2.15 & 812.1 & 1.1 \\
293.2 & 70.5 & 1002.8 & 1.1 & 342.6 & 3 & 815.5 & 1.1 \\
293.2 & 90.71 & 1020.6 & 1.1 & 342.6 & 5.17 & 823.5 & 1.1 \\
303.1 & 0.52 & 890.6 & 1.1 & 342.6 & 7.43 & 831 & 1.1 \\
303.1 & 0.98 & 891.7 & 1.1 & 342.5 & 13.31 & 848.2 & 1.1 \\
303.1 & 2.09 & 894.2 & 1.1 & 342.6 & 20.72 & 866.4 & 1.1 \\
303.2 & 5.56 & 901.6 & 1.1 & 342.6 & 22.8 & 871 & 1.1 \\
303.1 & 8.52 & 907.9 & 1.1 & 342.6 & 30.32 & 886.1 & 1.1 \\
303.1 & 11.08 & 912.8 & 1.1 & 342.6 & 50.28 & 918.8 & 1.1 \\
303.1 & 20.08 & 928.5 & 1.1 & 342.5 & 69.08 & 943.4 & 1.1 \\
303.1 & 30.52 & 944.3 & 1.1 & 342.5 & 90.25 & 966.7 & 1.1 \\
303.2 & 46.93 & 965.5 & 1.1 & 352.4 & 2.27 & 788.8 & 1.1 \\
303.1 & 51.59 & 971 & 1.1 & 352.4 & 5.25 & 802 & 1.1 \\
\hline & & & & & & &
\end{tabular}


Table 4 : (Continued)

\begin{tabular}{|c|c|c|c|c|c|c|c|}
\hline$T / \mathrm{K}$ & $p / \mathrm{MPa}$ & $\rho /\left(\mathrm{kg} \mathrm{m}^{-3}\right)$ & $U_{\rho} /\left(\mathrm{kg} \mathrm{m}^{-3}\right)$ & $T / \mathrm{K}$ & $p / \mathrm{MPa}$ & $\rho /\left(\mathrm{kg} \mathrm{m}^{-3}\right)$ & $U_{\rho} /\left(\mathrm{kg} \mathrm{m}^{-3}\right)$ \\
\hline 303.2 & 70.65 & 991.1 & 1.1 & 352.4 & 6.81 & 808.2 & 1.1 \\
\hline 303.2 & 90.72 & 1009.5 & 1.1 & 352.4 & 7.68 & 811.4 & 1.1 \\
\hline 313.0 & 0.67 & 871.5 & 1.1 & 352.4 & 9.33 & 817.3 & 1.1 \\
\hline 313.0 & 1.54 & 873.7 & 1.1 & 352.4 & 20.25 & 849 & 1.1 \\
\hline 313.0 & 2.58 & 876.5 & 1.1 & 352.4 & 30.6 & 872 & 1.1 \\
\hline 313.0 & 5.13 & 882.6 & 1.1 & 352.4 & 49.71 & 905.4 & 1.1 \\
\hline 313.0 & 7.13 & 887.2 & 1.1 & 352.4 & 70.97 & 934.4 & 1.1 \\
\hline 313.0 & 8.96 & 891.3 & 1.1 & 352.4 & 90.4 & 956.4 & 1.1 \\
\hline 313.0 & 10.88 & 895.4 & 1.1 & 362.3 & 5.8 & 781 & 1.1 \\
\hline 313.0 & 14.47 & 902.7 & 1.1 & 362.3 & 7.24 & 787.6 & 1.1 \\
\hline 313.0 & 20.92 & 914.5 & 1.1 & 362.2 & 8.28 & 792.5 & 1.1 \\
\hline 313.0 & 30.6 & 930.2 & 1.1 & 362.2 & 10.7 & 802.1 & 1.1 \\
\hline 313.0 & 49.8 & 956.3 & 1.1 & 362.2 & 21.95 & 836.9 & 1.1 \\
\hline 313.0 & 66.99 & 975.9 & 1.1 & 362.2 & 29.87 & 855.8 & 1.1 \\
\hline 313.0 & 88.11 & 996.6 & 1.1 & 362.2 & 36.77 & 869.9 & 1.1 \\
\hline 322.8 & 1.26 & 852.8 & 1.1 & 362.3 & 40.28 & 876.5 & 1.1 \\
\hline 322.8 & 2.31 & 855.9 & 1.1 & 362.2 & 50.5 & 894.1 & 1.1 \\
\hline 322.8 & 5.02 & 863.4 & 1.1 & 362.2 & 70.57 & 922.8 & 1.1 \\
\hline 322.8 & 7.6 & 870.1 & 1.1 & 362.2 & 90.22 & 946.1 & 1.1 \\
\hline 322.8 & 8.46 & 872.1 & 1.1 & & & & \\
\hline
\end{tabular}

${ }^{1} U_{\rho}$ is the expanded uncertainty of the density at a confidence level of $95 \%(k=2)$, composed of standard uncertainties of temperature $u_{T}=0.1 \mathrm{~K}$, pressure $u_{p}=0.002$ MPa, oscillation period $u_{s}=0.015 \mu \mathrm{s}$, calibration $u_{\text {cal }}=0.5 \mathrm{~kg} \mathrm{~m}^{-3}$ and impurities $u_{\mathrm{imp}}=0.2 \mathrm{~kg} \mathrm{~m}^{-3}$. 


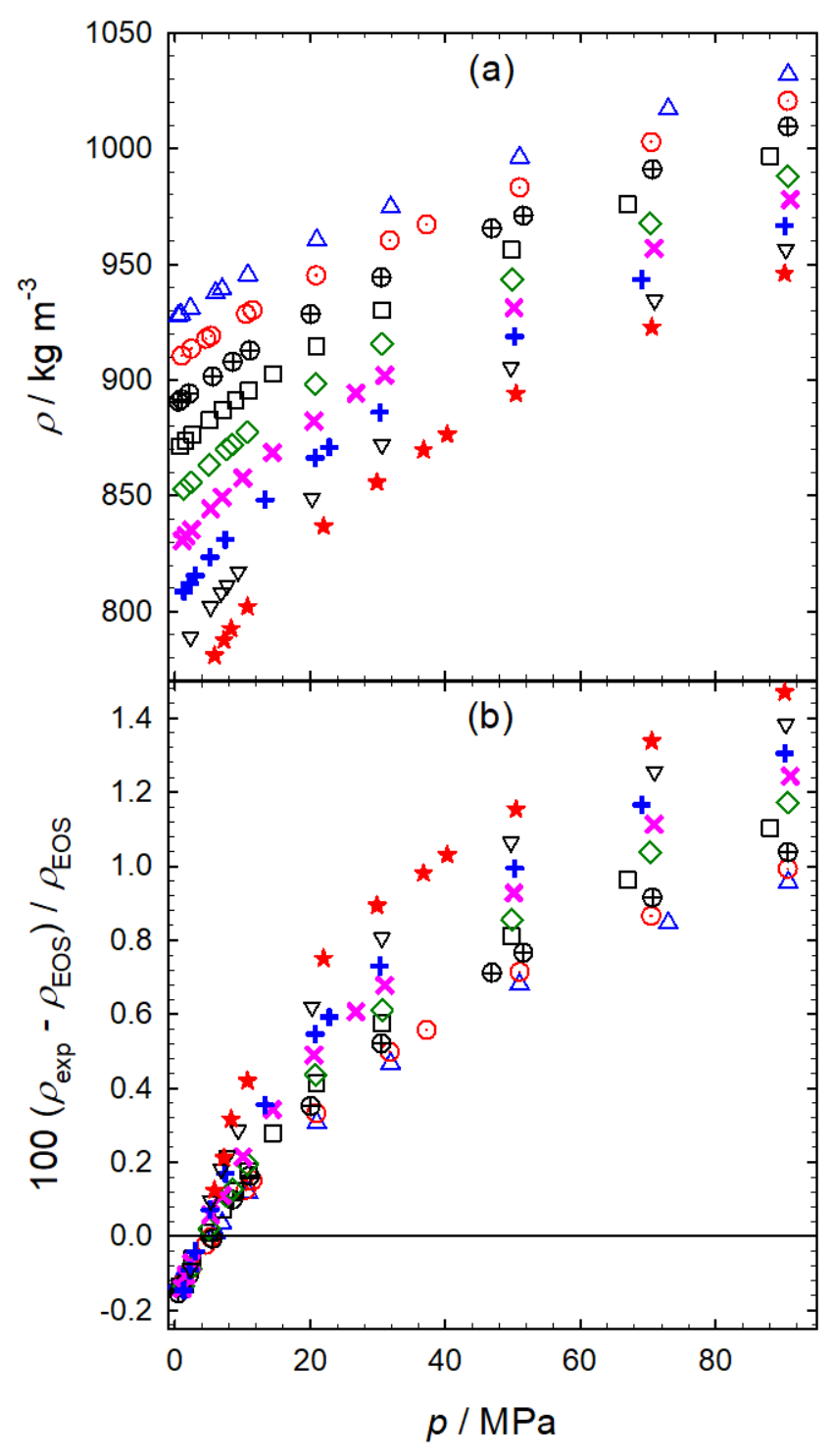

Figure 7: Density of vinyl chloride as a function of pressure (a) and deviation of the density data from the equation of state by Thol and $\operatorname{Span}^{17}$ (b): $\triangle 283 \mathrm{~K}, \odot 293 \mathrm{~K}, \oplus 303 \mathrm{~K}, \square$ $313 \mathrm{~K}, \diamond 323 \mathrm{~K}, \times 333 \mathrm{~K},+343 \mathrm{~K}, \nabla 352 \mathrm{~K}, \star 362 \mathrm{~K}$. 
The density of vinyl chloride as a function of pressure along the measured isotherms is depicted in Figure 7(a). The density ranges from $781.0 \mathrm{~kg} \mathrm{~m}^{-3}$ to $1031.9 \mathrm{~kg} \mathrm{~m}^{-3}$ and increases with falling temperature or rising pressure. Deviations of the density data from the Helmholtz energy equation of state by Thol and Span ${ }^{17}$ are shown in Figure $7(\mathrm{~b})$. It can be noted that performance of the equation of state is much better at low temperature and low pressure, were the deviations converge to $-0.15 \%$. At high pressures, the isotherms systematically diverge from the equation of state. The maximum deviation is $1.5 \%$ at the state point $362.2 \mathrm{~K}$ and $90.22 \mathrm{MPa}$. The experimental data at elevated temperatures and pressures indicate that the equation of state should be improved.

A comparison of the present density data with the experimental literature data is provided in Figure 8 and the base line is calculated with the equation of state of Thol and Span. ${ }^{17}$ Cullick and Ely ${ }^{12}$ as well as Zerfa and Brooks ${ }^{14}$ have measured the density of vinyl chloride above its vapor pressure, where the latter authors have measured only a single data point. This point has a deviation of $-0.18 \%$ from the equation of state. Cullick and Ely ${ }^{12}$ have reported the density along six isotherms, covering the temperature range between $281 \mathrm{~K}$ and $337 \mathrm{~K}$ with a pressure of up to $4.2 \mathrm{MPa}$. These data are in good agreement with the present work and show a similar trend. Their measurements exhibit a systematic behavior, where all isotherms cross the base line at a pressure between $2 \mathrm{MPa}$ to $4 \mathrm{MPa}$ with a maximum deviation of $0.1 \%$, except for the isotherm $337 \mathrm{~K}$, which has a noticeably different slope with a maximum deviation of about $1.6 \%$.

Table 5: Detailed uncertainty budget for the density measurement of vinyl chloride.

\begin{tabular}{cccccc}
\hline source & type & $\begin{array}{l}\text { measuring } \\
\text { range }\end{array}$ & $\begin{array}{l}\text { standard } \\
\text { uncertainty }\end{array}$ & $\begin{array}{c}\text { density } \\
\text { derivativa }^{\mathrm{a}}\end{array}$ & $\begin{array}{c}\text { relative expanded } \\
\text { uncertainty }^{\mathrm{a}}\end{array}$ \\
\hline temperature & - & - & $0.1 \mathrm{~K}$ & $1.5 \mathrm{~kg} \mathrm{~m}^{-3} \mathrm{~K}^{-1}$ & $0.016 \%$ \\
pressure & Keller-PAA-33X & $<100 \mathrm{MPa}$ & $0.02 \mathrm{MPa}$ & $0.2 \mathrm{~kg} \mathrm{~m}^{-3} \mathrm{MPa}^{-1}$ & $0.003 \%$ \\
oscillation period & - & - & $0.015 \mu \mathrm{s}$ & $1.310^{-7} \mathrm{~kg} \mathrm{~m}^{-3} \mathrm{~s}^{-1}$ & $0.028 \%$ \\
calibration & - & - & $0.5 \mathrm{~kg} \mathrm{~m}^{-3}$ & - & $0.109 \%$ \\
impurities & - & - & $0.2 \mathrm{~kg} \mathrm{~m}^{-3}$ & - & $0.044 \%$ \\
\hline
\end{tabular}

${ }^{\text {a }}$ Uncertainty value at a typical state point of $T=322.87 \mathrm{~K}$ and $p=30.62 \mathrm{MPa}$ for the present density measurement of vinyl chloride. 


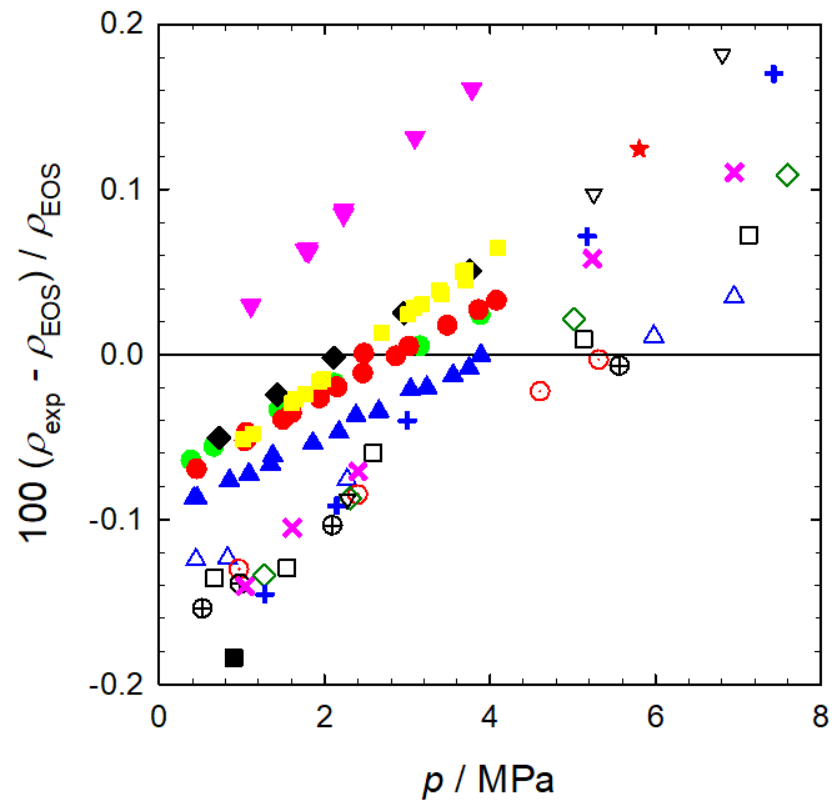

Figure 8: Deviation of the density data from the equation of state by Thol and Span ${ }^{17}$ in a region where other experimental data were available: this work; $\triangle 283 \mathrm{~K}$, $\odot 293 \mathrm{~K}, \oplus$ $303 \mathrm{~K}, \square 313 \mathrm{~K}, \diamond 323 \mathrm{~K}, \times 333 \mathrm{~K},+343 \mathrm{~K}, \nabla 352 \mathrm{~K}, \star 362 \mathrm{~K}$ : experiment literature data; Cullick and Ely ${ }^{12} \boldsymbol{\Delta} 281 \mathrm{~K}, \bullet 289 \mathrm{~K}, \bullet 295 \mathrm{~K}, 306 \mathrm{~K}, \square 318 \mathrm{~K}, \boldsymbol{\nabla} 337 \mathrm{~K}$; Zerfa and Brooks ${ }^{14} 328 \mathrm{~K}$. 


\subsection{Speed of sound}

Speed of sound data for vinyl chloride at different temperatures and pressures with uncertainty values are numerically listed in Table 6 . The overall expanded uncertainty of the speed of sound at a confidence level of $95 \%(k=2)$ consists of standard uncertainties of temperature $u_{T}$, pressure $u_{p}$, delay in time of flight $u_{\Delta t}$ and path length difference $u_{\Delta L}$ measurement

$U_{w}=k\left[\left(\frac{\partial w}{\partial T}\right)_{p, \Delta L, \Delta t}^{2} u_{T}^{2}+\left(\frac{\partial w}{\partial p}\right)_{T, \Delta L, \Delta t}^{2} u_{p}^{2}+\left(\frac{\partial w}{\partial \Delta L}\right)_{T, p, \Delta t}^{2} u_{\Delta L}^{2}+\left(\frac{\partial w}{\partial \Delta t}\right)_{T, p, \Delta L}^{2} u_{\Delta t}^{2}\right]^{1 / 2}$.

The partial derivatives of speed of sound with respect to temperature and pressure were calculated with the equation of state for vinyl chloride, ${ }^{17}$ while the derivatives with respect to delay in time of flight and path length difference were calculated from equation (3). A detailed uncertainty budget for the speed of sound measurement at a typical state point is provided in Table 7 . The expanded uncertainties of temperature, pressure and timing are below $0.02 \%$. The largest contribution to the overall uncertainty is due to path length calibration, i.e. $0.08 \%$, which includes a margin for reproducability of the calibration data at elevated temperatures and pressures. A graphical representation of the uncertainties shows that the overall expanded uncertainties are below $0.16 \%$ for the entire measured data set, cf. Figure 9. At pressures above $20 \mathrm{MPa}$, the uncertainties are below $0.1 \%$ throughout. As with the density data, uncertainties are large at high temperatures and low pressures because the speed of sound changes significantly in this region, cf. Figure 10(a).

The speed of sound of vinyl chloride as a function of pressure along nine isotherms is shown in Figure 10(a). It was measured over a wide span from $550.9 \mathrm{~m} \mathrm{~s}^{-1}$ to $1336.2 \mathrm{~m} \mathrm{~s}^{-1}$. A comparison of the present experimental data with the preliminary equation of state by

Thol and Span ${ }^{17}$ is shown in Figure 10(b). It should be noted that no experimental caloric data, e.g., speed of sound or heat capacity, were available in the literature when the equation 


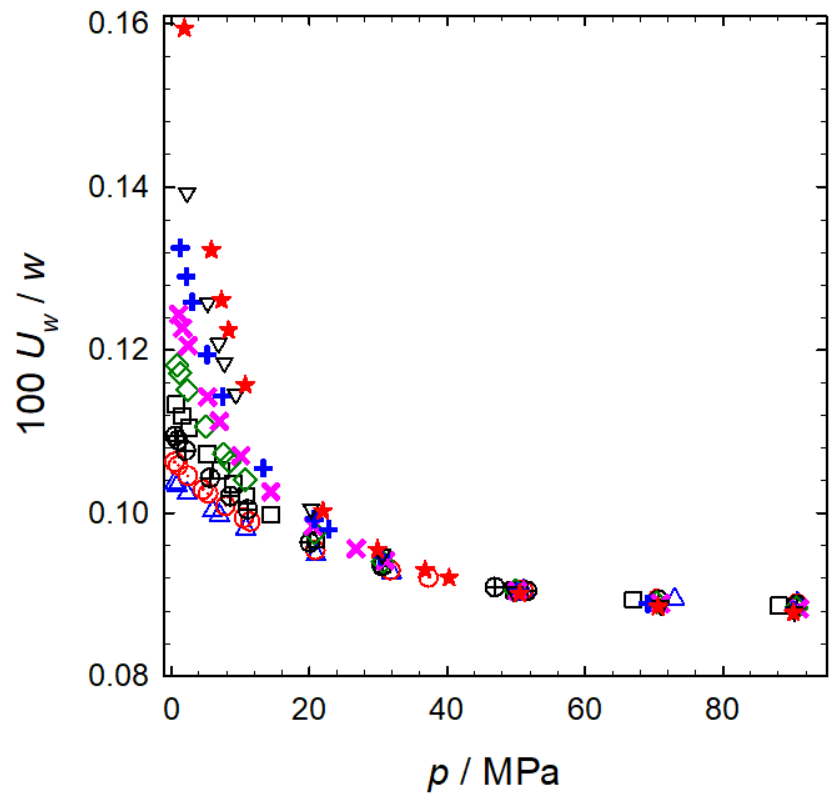

Figure 9: Experimental uncertainty of the speed of sound of vinyl chloride as a function of pressure along isotherms: $\triangle 284 \mathrm{~K}, \odot 294 \mathrm{~K}, \oplus 303 \mathrm{~K}, \square 313 \mathrm{~K}, \diamond 323 \mathrm{~K}, \times 333 \mathrm{~K},+342$ $\mathrm{K}, \nabla 351 \mathrm{~K}, \star 361 \mathrm{~K}$.

of state of Thol and Span ${ }^{17}$ was developed. As a consequence, the equation of state deviates by up to $-12.4 \%$ from the present experimental data. The divergence is high at low pressures for all isotherms. However, at high pressures, all isotherms are systematically approaching the equation of state with a minimum deviation of $-7.5 \%$.

Table 6: Speed of sound of vinyl chloride with its expanded experimental uncertainty for varying temperature $T$ and pressure $p$.

\begin{tabular}{cccccccc}
\hline$T / \mathrm{K}$ & $p / \mathrm{MPa}$ & $w /\left(\mathrm{m} \mathrm{s}^{-1}\right)$ & $U_{w} /\left(\mathrm{m} \mathrm{s}^{-1}\right)$ & $T / \mathrm{K}$ & $p / \mathrm{MPa}$ & $w /\left(\mathrm{m} \mathrm{s}^{-1}\right)$ & $U_{w} /\left(\mathrm{m} \mathrm{s}^{-1}\right)$ \\
\hline 283.96 & 0.45 & 935.3 & 1.0 & 322.48 & 8.46 & 817.3 & 0.9 \\
283.82 & 0.83 & 938.4 & 1.0 & 322.49 & 10.69 & 835.6 & 0.9 \\
283.97 & 2.27 & 948.1 & 1.0 & 322.61 & 20.78 & 907.9 & 0.9 \\
283.85 & 5.98 & 973.3 & 1.0 & 322.62 & 30.62 & 968.1 & 0.9 \\
283.92 & 6.96 & 979.5 & 1.0 & 322.64 & 49.89 & 1066.7 & 1.0 \\
283.86 & 10.77 & 1003.2 & 1.0 & 322.64 & 70.35 & 1153.5 & 1.0 \\
\hline
\end{tabular}


Table 6 : (Continued)

\begin{tabular}{|c|c|c|c|c|c|c|c|}
\hline$T / \mathrm{K}$ & $p / \mathrm{MPa}$ & $w /\left(\mathrm{m} \mathrm{s}^{-1}\right)$ & $U_{w} /\left(\mathrm{m} \mathrm{s}^{-1}\right)$ & $T / \mathrm{K}$ & $p / \mathrm{MPa}$ & $w /\left(\mathrm{m} \mathrm{s}^{-1}\right)$ & $U_{w} /\left(\mathrm{m} \mathrm{s}^{-1}\right)$ \\
\hline 283.87 & 20.97 & 1060.5 & 1.0 & 322.64 & 90.67 & 1228.0 & 1.1 \\
\hline 283.86 & 31.90 & 1114.8 & 1.0 & 332.33 & 1.03 & 697.8 & 0.9 \\
\hline 283.87 & 51.01 & 1197.1 & 1.1 & 332.33 & 1.61 & 704.5 & 0.9 \\
\hline 283.95 & 73.00 & 1278.1 & 1.1 & 332.35 & 2.40 & 713.4 & 0.9 \\
\hline 283.95 & 90.77 & 1336.2 & 1.2 & 332.33 & 5.24 & 743.4 & 0.8 \\
\hline 293.75 & 0.49 & 888.2 & 0.9 & 332.12 & 6.95 & 760.5 & 0.8 \\
\hline 293.53 & 0.97 & 891.4 & 0.9 & 332.12 & 10.02 & 788.6 & 0.8 \\
\hline 293.52 & 2.40 & 903.0 & 0.9 & 332.13 & 14.40 & 824.9 & 0.8 \\
\hline 293.50 & 4.61 & 919.3 & 0.9 & 332.13 & 20.56 & 870.5 & 0.9 \\
\hline 293.52 & 5.31 & 924.3 & 0.9 & 332.20 & 26.77 & 911.4 & 0.9 \\
\hline 293.76 & 7.84 & 940.1 & 0.9 & 332.18 & 31.05 & 937.6 & 0.9 \\
\hline 293.51 & 10.50 & 959.4 & 1.0 & 332.20 & 50.18 & 1038.8 & 0.9 \\
\hline 293.52 & 11.45 & 965.5 & 1.0 & 332.21 & 70.92 & 1129.2 & 1.0 \\
\hline 293.53 & 20.89 & 1021.6 & 1.0 & 332.22 & 91.06 & 1204.5 & 1.1 \\
\hline 293.53 & 31.77 & 1078.3 & 1.0 & 341.91 & 1.28 & 649.9 & 0.9 \\
\hline 293.63 & 37.25 & 1104.4 & 1.0 & 341.93 & 2.15 & 661.1 & 0.9 \\
\hline 293.54 & 51.02 & 1164.7 & 1.1 & 341.92 & 2.99 & 671.9 & 0.8 \\
\hline 293.63 & 70.49 & 1239.5 & 1.1 & 341.94 & 5.17 & 697.2 & 0.8 \\
\hline 293.65 & 90.70 & 1307.8 & 1.2 & 341.93 & 7.43 & 721.5 & 0.8 \\
\hline 303.22 & 0.52 & 840.6 & 0.9 & 341.82 & 13.32 & 776.7 & 0.8 \\
\hline 303.28 & 0.98 & 844.2 & 0.9 & 341.84 & 20.72 & 835.7 & 0.8 \\
\hline 303.30 & 2.08 & 853.5 & 0.9 & 341.84 & 22.80 & 850.9 & 0.8 \\
\hline 303.36 & 5.59 & 881.1 & 0.9 & 341.85 & 30.31 & 900.7 & 0.9 \\
\hline 303.22 & 8.52 & 903.1 & 0.9 & 341.86 & 50.27 & 1010.8 & 0.9 \\
\hline
\end{tabular}


Table 6 : (Continued)

\begin{tabular}{|c|c|c|c|c|c|c|c|}
\hline$T / \mathrm{K}$ & $p / \mathrm{MPa}$ & $w /\left(\mathrm{m} \mathrm{s}^{-1}\right)$ & $U_{w} /\left(\mathrm{m} \mathrm{s}^{-1}\right)$ & $T / \mathrm{K}$ & $p / \mathrm{MPa}$ & $w /\left(\mathrm{m} \mathrm{s}^{-1}\right)$ & $U_{w} /\left(\mathrm{m} \mathrm{s}^{-1}\right)$ \\
\hline 303.23 & 11.08 & 921.1 & 0.9 & 341.87 & 69.07 & 1095.7 & 1.0 \\
\hline 303.23 & 20.07 & 978.5 & 0.9 & 341.88 & 90.24 & 1177.5 & 1.0 \\
\hline 303.24 & 30.52 & 1036.5 & 1.0 & 351.50 & 2.27 & 612.1 & 0.9 \\
\hline 303.34 & 46.93 & 1115.0 & 1.0 & 351.51 & 5.25 & 652.1 & 0.8 \\
\hline 303.26 & 51.59 & 1135.3 & 1.0 & 351.49 & 6.81 & 670.9 & 0.8 \\
\hline 303.35 & 70.65 & 1210.7 & 1.1 & 351.51 & 7.68 & 680.8 & 0.8 \\
\hline 303.36 & 90.72 & 1280.4 & 1.1 & 351.49 & 9.34 & 698.9 & 0.8 \\
\hline 313.08 & 0.67 & 792.9 & 0.9 & 351.52 & 20.26 & 797.5 & 0.8 \\
\hline 312.84 & 1.54 & 801.7 & 0.9 & 351.46 & 30.59 & 871.0 & 0.8 \\
\hline 313.08 & 2.57 & 810.4 & 0.9 & 351.48 & 49.70 & 980.3 & 0.9 \\
\hline 312.86 & 5.13 & 833.2 & 0.9 & 351.50 & 70.98 & 1078.5 & 1.0 \\
\hline 312.86 & 7.13 & 849.6 & 0.9 & 351.53 & 90.39 & 1154.6 & 1.0 \\
\hline 312.85 & 8.96 & 863.9 & 0.9 & 361.21 & 1.89 & 550.9 & 0.9 \\
\hline 312.86 & 10.88 & 878.4 & 0.9 & 361.17 & 5.80 & 611.6 & 0.8 \\
\hline 312.89 & 14.47 & 903.8 & 0.9 & 361.10 & 7.24 & 631.0 & 0.8 \\
\hline 312.91 & 20.92 & 945.9 & 0.9 & 361.04 & 8.27 & 644.0 & 0.8 \\
\hline 312.91 & 30.59 & 1002.2 & 0.9 & 361.05 & 10.71 & 672.1 & 0.8 \\
\hline 312.92 & 49.80 & 1096.6 & 1.0 & 361.07 & 21.95 & 776.4 & 0.8 \\
\hline 312.92 & 66.99 & 1168.2 & 1.0 & 361.08 & 29.86 & 835.3 & 0.8 \\
\hline 312.91 & 88.10 & 1245.1 & 1.1 & 361.05 & 36.77 & 880.1 & 0.8 \\
\hline 322.73 & 0.82 & 745.5 & 0.9 & 361.11 & 40.28 & 901.4 & 0.8 \\
\hline 322.48 & 1.27 & 750.4 & 0.9 & 361.08 & 50.50 & 957.7 & 0.9 \\
\hline 322.49 & 2.31 & 761.0 & 0.9 & 361.10 & 70.56 & 1052.6 & 0.9 \\
\hline 322.50 & 5.02 & 787.0 & 0.9 & 361.13 & 90.22 & 1131.4 & 1.0 \\
\hline
\end{tabular}


Table $6:$ (Continued)

\begin{tabular}{|c|c|c|c|c|c|c|}
\hline$T / \mathrm{K}$ & $p / \mathrm{MPa}$ & $w /\left(\mathrm{m} \mathrm{s}^{-1}\right)$ & $U_{w} /\left(\mathrm{m} \mathrm{s}^{-1}\right)$ & $T / \mathrm{K}$ & $p / \mathrm{MPa} \quad w /\left(\mathrm{m} \mathrm{s}^{-1}\right)$ & $U_{w} /\left(\mathrm{m} \mathrm{s}^{-1}\right)$ \\
\hline 322.49 & 7.59 & 810.0 & 0.9 & & & \\
\hline
\end{tabular}

${ }^{1} U_{w}$ is the expanded uncertainty of speed of sound at a confidence level of $95 \%(k=2)$, composed of standard uncertainties of temperature $u_{T}=0.05 \mathrm{~K}$, pressure $u_{p}=0.02$ $\mathrm{MPa}$, delay in time of flight $u_{\Delta t}=0.002 \mu \mathrm{s}$ and path length difference $u_{\Delta L}=7 \mu \mathrm{m}$.

Table 7: Detailed uncertainty budget for the speed of sound measurement of vinyl chloride.

\begin{tabular}{|c|c|c|c|c|c|}
\hline source & type & $\begin{array}{l}\text { measuring } \\
\text { range }\end{array}$ & $\begin{array}{l}\text { standard } \\
\text { uncertainty }\end{array}$ & $\begin{array}{c}\text { speed of sound } \\
\text { derivative }^{\mathrm{a}}\end{array}$ & $\begin{array}{c}\text { relative expanded } \\
\text { uncertainty }^{\mathrm{a}}\end{array}$ \\
\hline temperature & PT-100 & $84-693 \mathrm{~K}$ & $0.05 \mathrm{~K}$ & $4.2 \mathrm{~m} \mathrm{~s}^{-1} \mathrm{~K}^{-1}$ & $0.017 \%$ \\
\hline pressure & Keller-PAA-33X & $<100 \mathrm{MPa}$ & $0.02 \mathrm{MPa}$ & $0.6 \mathrm{~m} \mathrm{~s}^{-1} \mathrm{MPa}^{-1}$ & $0.012 \%$ \\
\hline time & $\begin{array}{c}\text { oscilloscope } \\
\text { Agilent DSO1022A }\end{array}$ & - & $0.002 \mu \mathrm{s}$ & $4.7 \cdot 10^{7} \mathrm{~m} \mathrm{~s}^{-2}$ & $0.019 \%$ \\
\hline path length & - & - & $7 \mu \mathrm{m}$ & $4.8 \cdot 10^{4} \mathrm{~s}^{-1}$ & $0.080 \%$ \\
\hline
\end{tabular}

${ }^{\text {a }}$ Uncertainty value at a typical state point of $T=322.62 \mathrm{~K}$ and $p=30.6 \mathrm{MPa}$ for the present speed of sound measurement of vinyl chloride.

\section{Conclusions}

An apparatus was built to simultaneously measure the density and speed of sound of vinyl chloride. An Anton Paar densimeter was employed for the density measurement and was calibrated with propane and water. The maximum deviation of the density calibration measurements was $0.04 \%$ from the reference quality equation of state for propane by Lemmon et al. ${ }^{20}$ and $0.01 \%$ from the reference quality equation of state for water by Wagner and Pruß. ${ }^{21}$ For the speed of sound measurements, a double path length pulse-echo technique was implemented and the acoustic cell was calibrated with water. The calibration measurements have a maximum deviation of $0.02 \%$ from the equation of state by Wagner and Pruß. ${ }^{21}$

Density and speed of sound of vinyl chloride were investigated over a wide temperature range from $283 \mathrm{~K}$ to $362 \mathrm{~K}$ up to a pressure of $91 \mathrm{MPa}$. A detailed experimental uncertainty analysis was carried out. The maximum expanded uncertainty, at a confidence level of $95 \%$ 


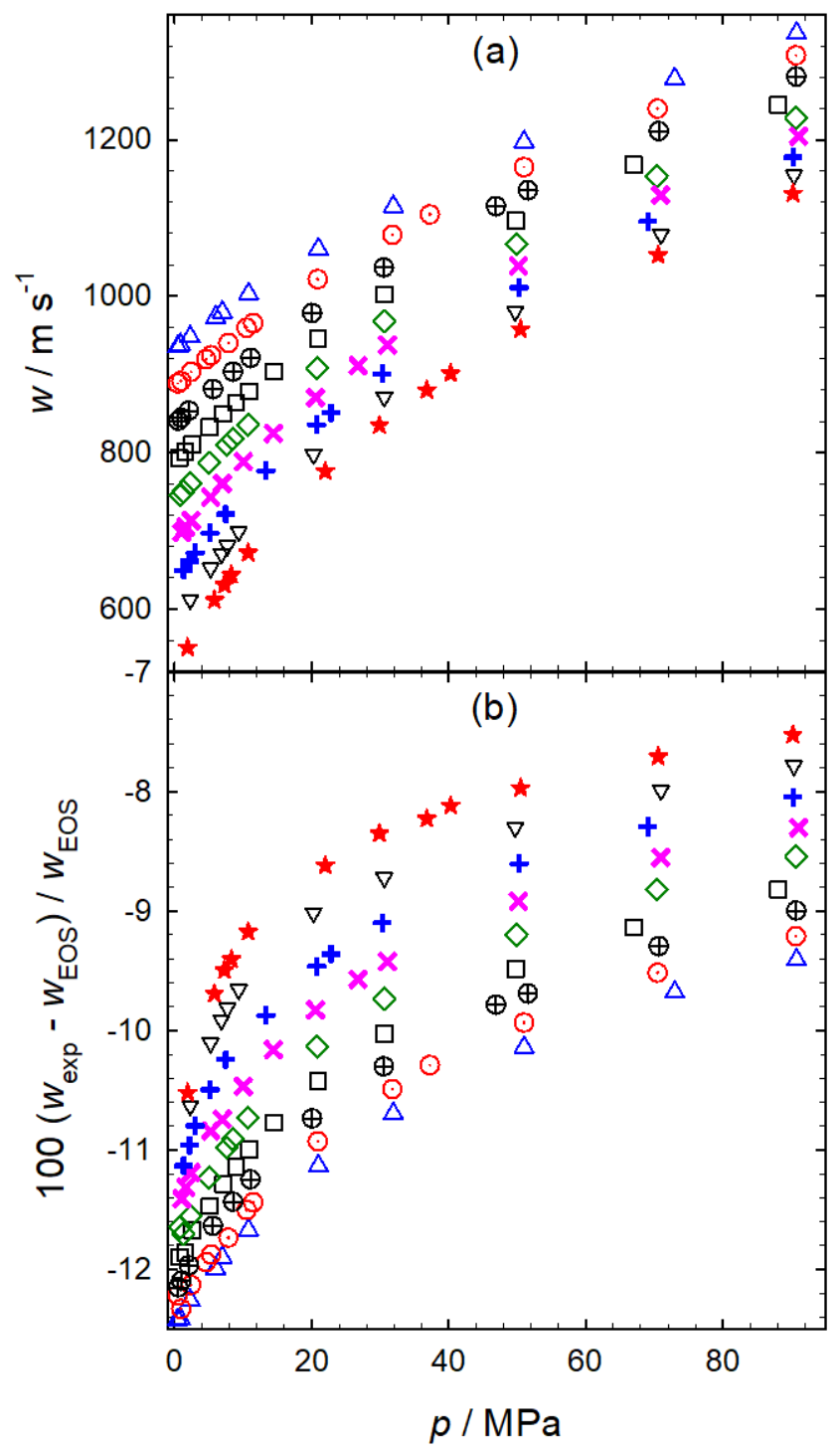

Figure 10: Speed of sound of vinyl chloride (a) and deviation of the present data from the equation of state by Thol and $\operatorname{Span}^{17}$ (b): $\triangle 284 \mathrm{~K}, \odot 294 \mathrm{~K}, \oplus 303 \mathrm{~K}, \square 313 \mathrm{~K}, \diamond 323 \mathrm{~K}$, $\times 333 \mathrm{~K},+342 \mathrm{~K}, \nabla 351 \mathrm{~K}, \star 361 \mathrm{~K}$. 
$(k=2)$, is $1.1 \mathrm{~kg} \mathrm{~m}^{-3}$ for the density and $1.2 \mathrm{~m} \mathrm{~s}^{-1}$ for the speed of sound measurements. Present results for the density of vinyl chloride were compared with the available literature data and the preliminary equation of state by Thol and Span. ${ }^{17}$ Only two authors have reported the density above the vapor pressure, i.e. Cullick and Ely ${ }^{12}$ as well as Zerfa and Brooks. ${ }^{14}$ Present data are in a good agreement with these literature data and have a maximum deviation of $1.5 \%$ from the equation of state. However, for the speed of sound of vinyl chloride, no literature data were found and the preliminary equation of state of Thol and Span ${ }^{17}$ diverges up to $-12.4 \%$ from the present data. Therefore, the preliminary equation of state for vinyl chloride should be refined on the basis of the present data.

\section{Acknowledgement}

The first author would like to thank the DAAD/HEC Pakistan scholarship program for financing this study.

\section{References}

(1) U.S. Department of Health and Human Services, Toxicological Profile for Vinyl Chloride. Update. Agency for Toxic Substances \& Disease Registry; 2006.

(2) Dreher, E. L.; Torkelson, T. R.; Beutel, K. K. "Chlorethanes and Chloroethylenes" in Ullmann's Encyclopedia of Industrial Chemistry; Wiley-VCH, Weinheim, 2011.

(3) Sherman, M. Vinyl Chloride and the Liver. J. Hepatol. 2009, 51, 1074-1081.

(4) Law Business Research, Global Vinyl Chloride Monomer (VCM) Industry Outlook to 2023 - Capacity and Capital Expenditure Forecasts with Details of All Active and Planned Plants; GlobalData, 2019. 
(5) Koon-Ling, R.; Maria, D. Chemical Economics Handbook: Vinyl Chloride Monomer $(V C M) ; 2019$.

(6) Magistro, A. J.; Cowfer, J. A. Oxychlorination of Ethylene. J. Chem. Educ. 1986, 63, $1056-1058$.

(7) Dana, L.; Burdick, J.; Jenkins, A. Some Physical Properties of Vinyl Chloride. J. Am. Chem. Soc. 1927, 49, 2801-2806.

(8) Mizutani, K.; Yamashita, K. Vinyl Chloride Resin Manufacturing Research. 2. Vinyl Chloride Physical Properties Using Analytical Methods. Tokyo Kogyo Shikensho Hokoku 1950, 45, 49-55.

(9) Dreisbach, R. R. Technical Report; 1952-1955.

(10) Confident. Comp. Res. Rep.; 1965.

(11) Hannaert, H.; Haccuria, M.; Mathieu, M. P. Solubility of Gaseous Hydrocarbons in Some Common Solvents. Ind. Chim. Belge 1967, 32, 156-164.

(12) Cullick, A. S.; Ely, J. F. Densities of Vinyl Chloride from 5 to 65 C and Saturation Pressure to 4.2 MPa. J. Chem. Eng. Data 1982, 27, 276-281.

(13) de Loos, T. W.; Van der Kooi, H. J.; Poot, W.; Ott, P. L. Fluid Phase Equilibria in the System Ethylene + Vinyl Chloride. Delft Prog. Rep., Ser. A 1983, 8, 200-213.

(14) Zerfa, M.; Brooks, B. Prediction of Vinyl Chloride Drop Sizes in Stabilised /LiquidLiquid Agitated Dispersion. Chem. Eng. Sci. 1996, 51, 3223-3233.

(15) Barsan, M. E. National Institute for Occupational Safety and Health: Pocket Guide to Chemical Hazards; NIOSH Publications, 2007. 
(16) Thol, M.; Javed, M. A.; Baumhögger, E.; Span, R.; Vrabec, J. Thermodynamic Properties of Dodecamethylpentasiloxane, Tetradecamethylhexasiloxane, and Decamethylcyclopentasiloxane. Ind. Eng. Chem. Res. 2019, 58, 9617-9635.

(17) Thol, M.; Span, R. Equation of State for Vinyl Chloride. Internal Report, RuhrUniversity Bochum, Germany, 2015.

(18) Platzer, N. A. J. Stabilization of Polymers and Stabilizer Processes Advances in Chemistry; American Chemical Society: Washington, DC, 1968.

(19) Terwiesch, B. Vinyl Chloride Peroxide Explosion in a Vinyl Chloride Recovery Plant. J. Macromol. Sci. 1982, 17, 1081-1092.

(20) Lemmon, E. W.; McLinden, M. O.; Wagner, W. Thermodynamic Properties of Propane. III. A Reference Equation of State for Temperatures from the Melting Line to $650 \mathrm{~K}$ and Pressures up to 1000 MPa. J. Chem. Eng. Data 2009, 54, 3141-3180.

(21) Wagner, W.; Pruß, A. The IAPWS Formulation 1995 for the Thermodynamic Properties of Ordinary Water Substance for General and Scientific Use. J. Phys. Chem. Ref. Data 2002, 31, 387-535.

(22) Outcalt, S. L.; McLinden, M. O. Automated Densimeter for the Rapid Characterization of Industrial Fluids. Ind. Eng. Chem. Res. 2007, 46, 8264-8269.

(23) Meier, K.; Kabelac, S. Speed of Sound Instrument for Fluids with Pressures up to 100 MPa. Rev. Sci. Instrum. 2006, r7, 123903.

(24) Gedanitz, H.; Dávila, M. J.; Baumhögger, E.; Span, R. An Apparatus for the Determination of Speeds of Sound in Fluids. J. Chem. Thermodyn. 2010, 42, 478-483.

(25) Javed, M. A.; Baumhögger, E.; Vrabec, J. Thermodynamic Speed of Sound Data for Liquid and Supercritical Alcohols. J. Chem. Eng. Data 2019, 64, 1035-1044. 
(26) Muringer, M.; Trappeniers, N.; Biswas, S. The Effect of Pressure on the Sound Velocity and Density of Toluene and n-Heptane up to 2600 bar. Phys. Chem. Liq. 1985, 14, 273296.

(27) Meier, K. The Pulse-Echo Method for High Precision Measurements of the Speed of Sound in Fluids. Postdoctoral Thesis, Department of Mechanical Engineering, HelmutSchmidt-Universitat/Universitat der Bundeswehr Hamburg 2006,

(28) Javed, M. A.; Baumhögger, E.; Vrabec, J. Thermodynamic Speed of Sound of Xenon. J. Chem. Thermodyn. 2020, 141, 105933.

(29) Lin, C. W.; Trusler, J. P. The Speed of Sound and Derived Thermodynamic Properties of Pure Water at Temperatures between (253 and 473) K and at Pressures up to 400 MPa. J. Chem. Phys. 2012, 136, 094511.

(30) Al Ghafri, S. Z.; Matabishi, E. A.; Trusler, J. M.; May, E. F.; Stanwix, P. L. Speed of Sound and Derived Thermodynamic properties of para-Xylene at Temperatures between (306 and 448) K and at Pressures up to 66 MPa. J. Chem. Thermodyn. 2019, 135, 369-381.

(31) Wilson, W. D. Speed of Sound in Distilled Water as a Function of Temperature and Pressure. J. Acoust. Soc. Am. 1959, 31, 1067-1072.

(32) Yebra, F.; Troncoso, J.; Romaní, L. Fully Automatized Apparatus for Determining Speed of Sound for Liquids in the Temperature and Pressure Interval (283.15-343.15) K and (0.1-95) MPa. J. Chem. Thermodyn. 2017, 104, 102-109.

(33) Benedetto, G.; Gavioso, R.; Albo, P. G.; Lago, S.; Ripa, D. M.; Spagnolo, R. Speed of Sound in Pure Water at Temperatures between 274 and $394 \mathrm{~K}$ and at Pressures up to 90 MPa. Int. J. Thermophys. 2005, 26, 1667-1680. 


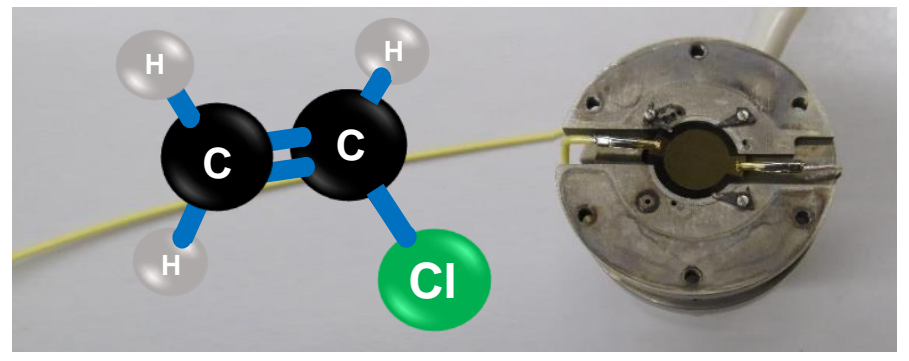

For Table of Contents Only 